\title{
Women Who Take Low-Dose Combined Oral Contraceptives have Greater Triglycerides to High Density Lipoprotein Ratio than Those Who do not Use
}

Diego Passos Diogo ${ }^{1,2}$, Alan Carlos Nery dos Santos ${ }^{1,2}$, Muriele Mascarenhas Lima ${ }^{3}$, Marvyn de Santana do Sacramento $^{4,5 *}$, Edna Conceição de Oliveira ${ }^{6}$, Ana Marice Teixeira Ladeia ${ }^{1}$, Armênio Costa Guimarães ${ }^{1}$ and Jefferson Petto ${ }^{1,4,5,6}$

${ }^{1}$ Bahiana School of Medicine and Public Health, Brazil

${ }^{2}$ Universidade Salvador, Brazil

${ }^{3}$ Feira de Santana State University, Brazil

${ }^{4}$ Actus Cordios Cardiovascular, Respiratory and Metabolic Rehabilitation, Brazil

${ }^{5}$ Brazil, Bahia Social University Center

${ }^{6}$ Bahia Adventist College, Brazil

Submission: April 22, 2020; Published: May 11, 2020

*Corresponding author: Marvyn de Santana do Sacramento, Actus Cordios Cardiovascular, Respiratory and Metabolic Rehabilitation. Salvador, BABrazil

\section{Abstract}

Introduction: It is known that the combined oral contraceptive (COC) use has been associated with increase cardiovascular risk markers, such a lipid metabolism modifications. Small dense LDL particles (LDL phenotype B) are described as being more atherogenic than larger buoyant ones and its presence in bloodis directly related to triglycerides (TG) to high density lipoprotein (HDL) ratio.

Aim: To test the hypothesis that women who take COC have greater values of TG / HDL ratio than those who do not take it.

Methods: The subjects consisted of women with age between 18 and 30 years old, irregular activity, eutrophics, with waist circumference $<80 \mathrm{~cm}$, blood glucose $<100 \mathrm{mg} / \mathrm{dL}$ and fasting triglycerides $<200 \mathrm{mg} / \mathrm{dL}$. The subjects were separated into two groups: 1) the group taking COC for at least one year (COG); 2) the group not taking any kind of hormonal contraceptive (NOCG).

Results: 106 volunteers were evaluated, which 52 of these were in the GCO. The means of TG / HDL ratio of the COG and NCOG were 2.1 $( \pm 0.8)$ vs $1.1( \pm 0.5)(p<0.01$; ES $=1.5)$, respectively. Still, the means of all lipid profile variables analyzed of COG were greater with statistic relevance than the other one.

Conclusion: Women who COC have TG / HDL ratio greater than those who do not take, suggesting the presence of lipid profile more atherogenic.

Keywords: Contraceptive Agents; Triglycerides; HDL Ratio; Cardiovascular Diseases; Lipid Metabolism

Abbreviations: COC: Combined Oral Contraceptive; HDL: High Density Lipoprotein; TG: Triglycerides; LDL: Low-Density Lipoprotein; CAD: Coronary Artery Disease; IPAQ: International Physical Activity Questionnaire

\section{Introduction}

The use of contraceptive methods for family planning has grown over the years among women of reproductive age (15-49 years old). In an exploratory analysis by using the United Nations Population Division database, the prevalence of contraceptive strategies worldwide increased from 55 percent up to 63 percent between 1990 and 2010 [1]. Among the reversible methods, oral contraceptives are presented as the most commonly used strategy for family planning. In Brazil, it is estimated that $27 \%$ of women including all social classes use some type of oral 


\section{Global Journal of Reproductive Medicine}

contraceptive [2]. In this context, combined oral contraceptives (COC) have been the choice options of a considerable part of the female population $[3,4]$. However, some investigations have shown that $\mathrm{COC}$ continued use is associated with the elevation of some cardiovascular risk markers, such as an increased insulin resistance [5] changes in the lipid profile [6] elevated blood pressure [7] and subclinical inflammation [8]. Low-density lipoprotein (LDL) is indicated as the main marker of the lipid profile involved in the atherosclerotic process of coronary artery disease (CAD) $[9,10]$. However, the quantification of LDL in clinical practice does not distinguish the heterogeneous group of subclasses that compose it. Based on the particle size and density lipid content, the LDL has been described in two different phenotypes basically: phenotype A and B [11]. Specifically, the LDL phenotype B subclass has a smaller size and higher density in its composition, suggesting to be more atherogenic class than the phenotype A. Studies have shown a 3-fold increased risk for CAD when it pattern of LDL predominates [12]. Environmental factors may influence the expression of this phenotype, such as continued use of oral contraceptives. The observational study conducted by Graaf et al. [13] corroborates with this hypothesis, which it was showed this association in premenopausal women who took low-dose COC. However, to quantify these subclasses it is commonly used density ultracentrifugation, an unusual method of direct analysis with a high cost for clinical practice. It is known that the presence of the phenotype of LDL subclass B has a close relationship with high value of serum triglycerides (TG) and low value of high density lipoprotein (HDL) $[11,14]$. This fact has been catch the scientific community attention, once the use of this TG / HDL ratio might be a method more accessible, user-friendly and low-cost for estimating the LDL subclasses presence $[14,15]$. Hanak et al. [14-19] showed an accuracy of $70 \%$ of this ratio when a cut-off point of 3.8 was established, based on the international recommendations for the desired fasting values of TG and HDL [10]. Due to the conclusiveness of these findings, the use of the TG / HDL ratio seems to be an interesting parameter to be used in the stratification of cardiovascular risk in the most varied populations, for example, in women who take hormonal contraceptives. Thus, this study aims to test the hypothesis that women who take COC have greater TG/HDL ratio values than those women who do not.

\section{Materials and Method}

It is aanalytic cross-sectional studyin which was included women between 18 and 30 years old, irregularly active, eutrophic, with waist circumference less than $80 \mathrm{~cm}$, with blood glucose less than $100 \mathrm{mg}$ / dl and fasting triglycerides less than $200 \mathrm{mg} / \mathrm{dL}$. The whole subjects were categorized into two groups: 1) contraceptive group (COG) composed of volunteers taking continuouslylowdose of COC of ethinylestradiol (15-30mcg) for at least one year; 2) non-contraceptive group (NCOG) composed of women who did not use any hormonal contraceptive method. For classifying the physical conditioning of the subjects it was used theshort version of International Physical Activity Questionnaire (IPAQ), in which was developed by the World Health Organization (WHO) and the Control Center and United States Prevention (Centers for Disease Control and Prevention, CDC) [16]. It was excluded of the study: women with dyslipidemias (diagnosed and / or under treatment), polycystic ovary syndrome, liver dysfunction, diabetes, hypo or hyperthyroidism, kidney disease, hypo or fat diet, alcohol consumption and smoking history, in use of lipid - lowering drugs, steroids, diuretics or beta-blockers. I was also excluded those who presented in the physical evaluation blood pressure (BP) values more than $140 / 90 \mathrm{mmHg}$. The sample calculation was performed in WinPepi calculator, where the difference between averages was established in 0.4 with a standard deviation of 0.6 , both extracted from a previous pilot study. It was considered an alpha of $5 \%$ and a beta of $80 \%$, in which a total of 37 volunteers for each group was required. It was followed the guidelines for the human being research written by the Helsinki Declaration and the National Health Council Resolution 466/12. This study was approved by the Ethics and Research Committee of Faculdade Nobre de Feira de Santana (CAAE number: 79549517.3.0000.5654) and all participants gave their informed consent.

\section{Physical and Clinical Procedures}

The volunteers were submitted to a standard questionnaire and physical examination in order to collect general information about their characteristics. Physical examination consisted of measurements of blood pressure (BP) at rest by using a mediumsized tensiometer for adults and calibrated by the National Institute of Metrology (INMETRO), in addition to a duo sonic stethoscope. This measurement followed the American Heart Association recommendations. Still, it was measured the total body weight and height. The measurement of height was performed with the subjects in completely stand up position and barefoot by using a professional stadiometer with $0.1 \mathrm{~cm}$ of precision. Total body weight was measured by using a digital device with maximum capacity of $150 \mathrm{~kg}$ and $\pm 100 \mathrm{~g}$ of margin of error. For the calculation of body mass index (BMI), the measures of body weight and height were used, according to the Quetelet equation: BMI = weight $(\mathrm{kg})$ / height ${ }^{2}(\mathrm{~m})$. For classification in eutrophic (18.5-24.9kg / $\left.\mathrm{m}^{2}\right)$, the cut-off points recommended by the V Brazilian Guidelines for Dyslipidemias and Prevention of Atherosclerosis 17 were adopted.

\section{Laboratory Collection}

After 12 hours of fasting, $10 \mathrm{~mL}$ of venous blood was drawn and serum concentrations of TG, total cholesterol (CT), LDL, HDL, Very Low Density Lipoprotein (VLDL) and blood glucose (BG) were analyzed. The evaluation of CT, HDL and TG was determined enzymatically. LDL was calculated by the Friedwald equation [18] and non-HDL cholesterol was calculated by the difference between total cholesterol and HDL. TG / HDL-c ratio values were obtained from these pre-established variables. Regarding the blood glucose analysis, it was used clinical chemistry system Dade Behring- Dimension, an in vitro diagnostic test for the 


\section{Global Journal of Reproductive Medicine}

quantitative determination of plasma glucose. The volunteers were instructed not to change their diet on the test week and to avoid any unusual physical activity, as well as not to drink alcohol in the 24 hours before the collection date. The collections were performed between the fifth and tenth day of the menstrual cycle with aim of smaller fluctuations hormone, and / or 28 days without medication (inactive phase) as recommended by Casazza et al. [19]. Thus, there will not be influence of menstruation on the variables values.

\section{Statistical Analysis}

It was used the symmetry and kurtosis test and the Shapiro Wilk test to verify the data, as well as the visual inspection of the histograms. As the variables presented normal distribution, they were described in mean and standard deviation. Thus, Student's t test for independent samples was performed to compare means. For the effect size calculation, the Cohen d score was performed for independent samples [20]. All analyzes were performed in the statistical package SPSS (Statistical Package for the Social Sciences) version 21.0, adopting a level of significance of $5 \%$.

\section{Results}

The population included 106 women, 52 in the COG. The clinical and anthropometric variables of both groups are described in Table 1. There was no statistical significance among them in the hypothesis test, showing homogeneity of these characteristics among the groups evaluated. Table 2 shows the fasting lipid profile of both groups. It is interesting to note that for all analyzed variables the COG showed significantly higher averages, including those involved in TG / HDL ratio calculation. Intergroup comparison of TG / HDL ratio values is described in Table 3. Besides the COG to present a statistically higher value in the applied test, a high effect size can be observed, which confirms the significance of the finding.

Table 1: Clinical and anthropometric variables of the study population.

\begin{tabular}{|c|c|c|c|}
\hline & COG (mean \pm SD) & NCOG (mean \pm SD) & P value * \\
\hline Age (years) & $23( \pm 2.5)$ & $23( \pm 2.5)$ & 0.36 \\
\hline BW $(\mathrm{kg})$ & $58( \pm 9.1)$ & $55( \pm 8.5)$ & 0.28 \\
\hline Height $(\mathrm{cm})$ & $161( \pm 5.7)$ & $163( \pm 5.7)$ & 0.15 \\
\hline BMI $\left(\mathrm{kg} / \mathrm{m}^{2}\right)$ & $22( \pm 2.3)$ & $21 \pm 3.2)$ & 0.07 \\
\hline SBP $(\mathrm{mmHg})$ & $109( \pm 11.6)$ & $106( \pm 8.5)$ & 0.33 \\
\hline DBP $(\mathrm{mmHg})$ & $70( \pm 8.4)$ & $68(7.9)$ & 0.54 \\
\hline BG & $82( \pm 6.1)$ & $84( \pm 7.3)$ & 0.23 \\
\hline
\end{tabular}

COG: Contraceptive Oral Group; NCOG: Non-Contraceptive Oral Group; BW: Body Weight; BMI: Body Mass Index; SBP: Systolic Blood Pressure; DBP: Diastolic Blood Pressure; SD: Standard Deviation; BG: Blood Glucose. *Student's t test for independent samples.

Table 2: Fasting lipid profile (mg/dL) of the sample studied.

\begin{tabular}{|c|c|c|c|}
\hline & COG (mean \pm SD) & NCOG (mean \pm SD) & P value * \\
\hline TG & $104( \pm 33.9)$ & $53( \pm 14.7)$ & 0.01 \\
\hline HDL & $54( \pm 12.6)$ & $50( \pm 11.1)$ & $<0.01$ \\
\hline CT & $204( \pm 41.3)$ & $170( \pm 35.3)$ & $<0.01$ \\
\hline LDL & $128( \pm 36.4)$ & $108(33.9)$ & $<0.01$ \\
\hline VLDL & $18( \pm 4.9)$ & $10( \pm 3.1)$ & \\
\hline
\end{tabular}

COG: Contraceptive Oral Group; NCOG: Non-Contraceptive Oral Group; TG: Triglycerides; CT: Total Cholesterol; HDL: High Density Lipoprotein; LDL: Low Density Lipoprotein; VLDL: Very Low Density Lipoprotein; SD: Standard Deviation *Student $t$ test for independent samples

Table 3: TG/HDL ratio between the groups studied.

\begin{tabular}{|c|c|c|c|c|}
\hline & COG $($ Mean \pm SD) & NCOG (Mean \pm SD) & p Value* & ES** \\
\hline TG/HDL ratio & $2.1 \pm 0.8)$ & $1.1( \pm 0.5)$ & $<0.01$ & 1.5 \\
\hline
\end{tabular}

COG: Contraceptive Oral Group; NCOG: Non-Contraceptive Oral Group; TG: Triglycerides; CT: Total Cholesterol; HDL: High Density Lipoprotein LDL: Low Density Lipoprotein; VLDL: Very Low Density Lipoprotein; SD: Standard Deviation; ES: Effect Size Performed by the Cohen d Score. * Student t-test for independent samples. 


\section{Global Journal of Reproductive Medicine}

\section{Discussion}

The results show that continued use of low-dose combined oral contraceptives (COC) is strongly associated with elevated TG / HDL ratio. This suggests that the profile of LDL in this population is more atherogenic, that is, it has smaller size and more density (subclass of phenotype B). Although the design of this study does not allow to establish a causal relationship between use of contraceptive pill and changes in the lipid profile, some investigations have already pointed out to it $[5,6,13]$. Some hypotheses try to explain possible mechanisms involved in the alterations of the lipid profile on this specific population. It is well documented that in the presence of insulin resistance, in which is one of the criteria for metabolic syndrome diagnosis, changes in the lipid profile occur $[5,21]$. Subjects who present LDL phenotype B predominance have twice more chance to develop type 2 diabetes, regardless of age, sex and body mass index [12]. But what explains this interrelationship? The blocking insulin action in the adipose tissue results in elevation of remaining chylomicrons and plasma free fatty acids. This leads to an increase in hepatic cellular activity and promote a negative repercussion in the quantitative lipid content and quality of the lipoproteins [11,21]. Responsible for promoting the deposition of TG in lipoproteins, the cholesteryl ester transport protein (CETP) is a determining factor in this metabolic pathway.

Pietzsch and Fuecker [22] identified an increase in CETP activity in individuals with insulin resistance compared to normoglycemics. In the work of Frempong et al. [5] poorer performance in the glucose tolerance test was identified in AfricanAmerican women using low-dose oral contraceptives in relation to those who did not use these hormones. Interestingly, there was no any difference in serum LDL levels between the groups studied. The differences identified were only the highest values of TG and HDL in the contraceptive group. This finding reinforces the idea that, most likely, LDL in the contraceptive group had a more atherogenic phenotype.

Moreover, it seems that these alterations are closely related to the estrogen and progestin dosages in the contraceptive composition [23-25]. The idea is that the chronic exposure to these hormones leads to enzymatic and endocrine changes that affect the lipid metabolism [26]. It is known that LDL size is determined by a genetic component in approximately $35 \%[12,27]$. However, environmental factors such as abdominal adiposity and a highcarbohydrate diet can influence the LDL profile [28,29]. In the present study, only women with an abdominal circumference $<80 \mathrm{~cm}$ and eutrophic were included, which excludes this methodological bias. Although there was no adequate control of the diet, the volunteers of both groups did not practice regular physical activities and belonged to the same social context, characterizing certain homogeneity between the groups. The TG / HDL ratio has been described as an important predictor of cardiovascular risk in different populations [30-32]. Specifically in women, this index was an independent predictor of mortality after adjustment for the other known risk factors [30]. Although there is no consensus regarding a specific cut-off point, Hanak et al. [14] identified that $89 \%$ of women with an index above 3.8 had a predominance of LDL of phenotype $B$, that is, with greater atherogenic power. This cut-off point established by the authors was based on the maximum and minimum values of TG and HDL respectively, according to international guidelines [10]. Interestingly, in the results found here, even though both groups are well below the 3.8 value, the group of women who use COC presents significantly higher average values in relation to control group. Thus, it seems that the continued use of this substance results in metabolic changes, for example, changes in the LDL profile. In fact, Graaf et al. [13] by using the density ultracentrifugation method showed a positive association between COC use and the predominance of smaller size and higher density fractions of LDL in premenopausal women. These findings corroborate with the results of the present study, since these authors used a method of direct quantification of the LDL subclasses. However, even with a higher ratio than the control group, does this index have any clinical significance since it is still below 3.8?. Some investigations have shown that coronary heart patients have LDL serum within normal values [33-36]. Sachdeva et al. [36] identified that approximately 75\% of patients hospitalized with CAD had their LDL levels absolutely normal, which drawing an important attention. But what explains such a finding like this? A consistent hypothesis of thinking is that for these individuals there would be a predominance of the $\mathrm{B}$ subtype of LDL. Thus, even if LDL levels are according to normal range, perhaps the main contribution regarding the lipid profile to increase cardiovascular risk is due to the predominance of the more atherogenic subclass of this lipoprotein. Tornvall et al. [34] showed a positive association between LDL subclass B in patients who suffered myocardial infarction. However, there was no any difference between TG and LDL values between these and the control group. Similarly, Campos et al. [33] identified significantly higher values of TG in patients with CAD compared with control, but without significant difference regarding LDL. Thus, it seems that the TG / HDL ratio offers additional information about the atherogenic risk of LDL, suggesting being an interesting marker during the clinical follow-up of women who use COC. Questions are raised up about the accuracy of this index. Among the methods used for direct quantification of LDL subtypes, magnetic resonance imaging (MRI) is described as a gold standard because of its ability to measure size of the lipoprotein and the concentration of its lipid content [37]. Thus, some researchers have evaluated the level of agreement between TG / HDL ratio and MRI with respect to the prediction of LDL phenotype B. By using the value of 3.8 as the cut-off point, Bhalodkar et al. [15] found a positive and negative predictive value of $83 \%$ and $89 \%$, respectively. In another investigation with the same purpose, this ratio was described with an accuracy of $70 \%$ [14]. Due to the variability of the population studied by the different researches, there is still no consensus in 


\section{Global Journal of Reproductive Medicine}

relation to what index should be adopted in the clinical context. However, it is clear that the higher this index, the greater probability of LDL phenotype B predominate. With regarding to women in continuous use of $\mathrm{COC}$, there appear to be strict relationship between the using time of drug and changes in the lipid profile Barry et al. [6] performed a subgroup analysis in their study in which they identified a direct relationship between the time of COC use and the serum levels of TG, HDL, VLDL. However it was showed an inverse relationship between this variable and the LDL quantity, which will consequently affect the TG / HDL ratio. Finally, it is important to note that although the TG / HDL ratio is higher in women taking COC, which may imply a higher risk of developing cardiovascular disease, the TG / HDL ratiois within normal limits. Therefore, it is imperative that physicians assess the benefits and risks individually before prescribing the use of COC, considering elements such as physical exercise, nutritional status, family history and other triggering factors of cardiovascular diseases, choosing the most appropriate contraceptive method.

\section{Conclusion}

Continued use of low-dose combined oral contraceptive is strongly associated with changes in the lipid profile of young women, resulting in elevation in Triglycerides / High Density Lipoprotein ratio. This suggests that this population has metabolic alterations in which can impact the Low-Density Lipoprotein profile and increase the cardiovascular risk.

\section{Financing Source}

This study obtained funding from the Bahia State Research Support Foundation (FAPESB) through the granting of a master's degree to Diego Passos Diogo.

\section{Academic Link}

This article represents part of the master dissertation of Diego Passos Diogo by the Bahian School of Medicine and Health Publica - EBMSP, Salvador, BA - Brazil.

\section{References}

1. Alkema L, Kantorova V, Menozzi C, Biddlecom A (2013) National, regional, and global rates and trends in contraceptive prevalence and unmet need for family planning between 1990 and 2015: A systematic and comprehensive analysis. Lancet 381(9878): 1642-1652.

2. (2009) BRASIL. Pesquisa Nacional de Demografia e Saúde da Criança e da Mulher: PNDS 2006: Dimensões do Processo Reprodutivo e da Saúde da Criança.

3. Brito MB, Nobre F, Vieira CS (2010) Contracepção hormonal e sistema cardiovascular. Soc Bras Cardiol 96(4): e81-e89.

4. WHO (2015) Medical Eligibility criteria for Contraceptive Use, pp. $1-276$.

5. Frempong B a, Ricks M, Sen S, Sumner AE (2008) Effect of low dose oral contraceptives on metabolic risk factors in African-American women. J Clin Endocrinol Metab 93(6): 2097-2103.

6. Abdel Barry JA, Flaf MS, Al Namaa LM, Hassan NA (2011) Lipoprotein changes in women taking low-dose combined oral contraceptive pills:
A cross-sectional study in Basra, Iraq. East. Mediterr Heal J 17(9): 684688.

7. Harvey RE, Hart EC, Charkoudian N, Curry TB, Carter JR, et al. (2015) Oral Contraceptive Use, Muscle Sympathetic Nerve Activity, and Systemic Hemodynamics in Young Women. Hypertension 66(3): 590597.

8. Petto J, Pereira LS, Santos ACN, Giesta BA, Melo TA, Ladeia AMT Inflamação Subclínica em Mulheres que Utilizam Contraceptivo Oral. Rev. Bras. Cardiol. 2013;26(6):465-471.

9. Kannel WB, Castelli WP, Gordon T, Mcnamara PM (1971) Serum Cholesterol, Lipoproteins, and the Risk of Coronary Heart Disease The Framingham Study. Ann Intern Med January 74(1): 1-12.

10. (2002) Services UD of H and H Third report of the National Cholesterol Education Program (NCEP) Expert Panel on Detection, Evaluation, and Treatment of High Blood Cholesterol in Adults (Adult Treatment Panel III): final report. Public Natl Cholest Educ Program, Natl. Hear. Lung, Blood Institute, Natl. Institutes Heal 5215(02).

11. Mudd JO, Borlaug BA, Johnston PV, Kral BG, Rouf R, et al. (2007) Beyond Low Density Lipoprotein Cholesterol. Defining the Role of Low-Density Lipoprotein Heterogeneity in Coronary Artery Disease. J Am Coll Cardiol 50(18): 1735-1741.

12. Austin MA, King MC, Vranizan KM, Newman B, Krauss RM (1988) Inheritance of low-density lipoprotein subclass patterns: results of complex segregation analysis. Am J Hum Genet 43(6): 838-846.

13. Graaf J, Swinkels DW, Demacker PNM, Haan AFJ SA (1993) Differences in the Low Density Lipoprotein Profile between Oral- Contraceptive Users. J Clin Endocrinol Metab 76(1): 197-202.

14. Hanak V, Munoz J, Teague J, Stanley A, Bittner V (2004) Accuracy of the triglyceride to high-density lipoprotein cholesterol ratio for prediction of the low-density lipoprotein phenotype B. Am J Cardiol 94(2): 219222.

15. Bhalodkar NC, Blum S, Enas EA (2006) Accuracy of the ratio of triglycerides to high-density lipoprotein cholesterol for predicting lowdensity lipoprotein cholesterol particle sizes, phenotype B, and particle concentrations among Asian Indians. Am J Cardiol 97(7): 1007-1009.

16. (2017) Centers for disease control and prevention - CDC. Surveillance Systems.

17. SBC SB de C (2013) V Diretriz Brasileira de Dislipidemias e Prevenção da Aterosclerose. Arq Bras Cardiol 101(4 Supl): 1-22.

18. Friedewald WT, Levy RI, Fredrickson DS (1972) Estimation of the concentration of low-density lipoprotein cholesterol in plasma, without use of the preparative ultracentrifuge. Clin Chem 18(6): 499-502.

19. Casazza GA, Suh SH, Miller BF, Navazio FM, Brooks GA (2002) Effects of oral contraceptives on peak exercise capacity. J. Appl. Physiol 93(5): 1698-1702.

20. Espirito Santo H, Daniel FB (2015) Calcular e apresentar tamanhos do efeito em trabalhos científicos (1): As limitações do $p<0,05$ na análise de diferenças de médias de dois grupos. Revista Portuguesa De Investigação Comportamental e Social 1(1): 3-16.

21. Cianflone K, Paglialunga S (2006) Regulation of fatty acid transport and storage: Influence of acylation-stimulating protein. Scand. J Food Nutr 50(Suppl 2): 92-98.

22. Pietzsch J, Fuecker K (2003) Increased cholesteryl ester transfer protein activity in impaired glucose tolerance: relationship to high density lipoprotein metabolism. Croat Med J 44(2): 171-177.

23. Schaefer EJ, Foster DM, Zech LA, Lindgren FT, Brewer HB, et al. (1983) The effects of estrogen administration on plasma lipoprotein metabolism in premenopausal females. J Clin Endocrinol Metab 57(2): 
262-267.

24. Crook D, Godsland IF, Wynn V (1988) Oral contraceptives and coronary heart disease: Modulation of glucose tolerance and plasma lipid risk factors by progestins. Am J Obstet Gynecol 158(6): 1612-1620.

25. Fotherby K (1985) Oral contraceptives, lipids and cardiovascular disease. J Contracept 31(4).

26. Tikkanen MJ NE(1987) Regulation of hepatic lipase and serum lipoproteins by sex steroids. Am Hear J 113: 562-567.

27. Austin MA (1992) Genetic epidemiology of low density lipoprotein subclass phenotypes. Ann Med 24(6): 477-481.

28. Terry RB, Stefanick ML, Haskell WL, Wood PD (1991) Contributions of regional adipose tissue depots to plasma lipoprotein concentrations in overweight men and women: Possible protective effects of thigh fat. Metabolism 40(7): 733-740.

29. Kim S, Lee H, Lee DC, Lee HS, Lee JW (2014) Predominance of small dense LDL differentiates metabolically unhealthy from metabolically healthy overweight adults in Korea. Metabolism 63(3): 415-421.

30. Bittner V, Johnson BD, Zineh I, Rogers WJ, Vido D, et al. (2003) The TG/ HDL Cholesterol Ratio Predicts All Cause Mortality in Women With Suspected Myocardial Ischemia A Report from the Women's Ischemia Syndrome Evaluation (WISE). Am Hear J 157(3): 548-555.

31. Luz PL da, Favarato D, Faria Neto Junior JR, Lemos P, Chagas ACP (2008) High ratio of triglycerides to hdl-cholesterol predicts extensive coronary disease. Clinics 63(4): 427-432.
32. Wan K, Zhao J, Huang H, Zhang Q, Chen X, et al. (2015) The association between triglyceride/high-density lipoprotein cholesterol ratio and all-cause mortality in acute coronary syndrome after coronary revascularization. PLoS One 10(4): 1-11.

33. Campos H, Genest JJ, Blijlevens E, Mc Namara JR, Jenner JL, et al.(1992) Low density lipoprotein particle size and coronary artery disease. Arterioscler. Thromb Vasc Biol 12(2): 187-195.

34. Tornvall P, Karpe F, Carlson LA, Hamsten A (1991) Relationships of low density lipoprotein subfractions to angiographically defined coronary artery disease in young survivors of myocardial infarction. Atherosclerosis 90(1): 67-80.

35. Coresh J, Kwiterovich PO, Smith HH, Bachorik PS (1993) Association of plasma triglyceride concentration and LDL particle diameter, density, and chemical composition with premature coronary artery disease in men and women. J Lipid Res 34(10): 1687-1697.

36. Sachdeva A, Cannon CP, Deedwania PC, La Bresh KA, Smith SC, et al. (2009) Lipid levels in patients hospitalized with coronary artery disease: An analysis of 136,905 hospitalizations in Get with the Guidelines. Am Heart J 157(1): 111-117.

37. Otvos JD, Jeyarajah EJ, Bennett DW (1991) Quantification of plasma lipoproteins by proton nuclear magnetic resonance spectroscopy. Clin Chem 37(3): 377-386.

\section{Your next submission with Juniper Publishers will reach you the below assets}

- Quality Editorial service

- Swift Peer Review

- Reprints availability

- E-prints Service

- Manuscript Podcast for convenient understanding

- Global attainment for your research

- Manuscript accessibility in different formats

( Pdf, E-pub, Full Text, Audio)

- Unceasing customer service

Track the below URL for one-step submission https://juniperpublishers.com/online-submission.php 